\title{
School Leadership for Sustaining Pedagogical Innovation such as Inquiry based Learning in ICT Implementation: An Experimental Evaluation of a High School in India
}

\author{
Jayati Bhattacharjee, Alka Muddgal
}

\begin{abstract}
This paper is a case study of a high school in India. The main purpose of the study is to investigate the key determinants of a school's success in initiating and sustaining pedagogical innovation such as Inquiry based learning through implementation of Information and Communication Technology with a specific objective on the effect of Leadership approaches on the change process. With the focus point on a High school, the study examined how the teaching staff of grades 6 and 7 succeeded in transforming from a semi-ICT based school to an ICT based school in terms of immersion of iPad and SEQTA learning management system. The study is based on descriptive and interpretive analysis of Questionnaires and Interviews. Three main findings of the study revealed that Collaborative Leadership was at the core of managing ICT integration successfully. The findings highlight the importance of fostering the future leaders for sustaining inquiry based good practices of ICT integration. Finally the study reflects upon the potential impact of leadership approaches on teachers' engagement in the change process of ICT implementation. There is limited research on Leadership approach to sustainability of ICT immersion in schools in India. The present study could serve as a reference for further research in this in this field.
\end{abstract}

Keywords : Pedagogical innovation, ICT integration, iPad and Learning Management System, Collaborative leadership, sustainability, inquiry based approach..

\section{INTRODUCTION}

Let us begin with the understanding of the term Innovation. 'Creativity is thinking up new things. Innovation is Doing New Things' (Theodore Levitt)

International studies of change management and ICT integration in schools have given evidence of a growing concern over the introduction and extension of the use of ICT over recent years (e.g. Wong \& Li 2006; Owston 2007). One of the aims of implementing ICT in schools is to change and improve existing teaching practices. This belief that ICT can play a key role in reforming education systems is reflected in similar agendas elsewhere in much

Revised Manuscript Received on October 15, 2019.

* Correspondence Author

Ms. Jayati Bhattacharjee, Research Fellow, Amity Institute of Education, Amity University, Noida

Dr.(Prof)Alka Muddgal, Head of Department, Amity Institute of Education, Amity University, Noida

of the industrialised world (e.g., DFEE, UK, 1997; MOE, Singapore, 2000; DE, Victoria, 1998; MOE, Research, and Church Affairs, Norway, 2000). These reform agendas are all concerned with the adoption and use of ICT in schools to increase learning opportunities and student motivation and achievement. These policies state that the introduction of ICT into educational environments will accelerate change and ultimately improve student learning. The report also shows the way of Harnessing Data management as a way to sustainable growth.

The goal 4 of the UNESCO's sustainable development goals report is to ensure inclusive and equitable quality education and promote lifelong opportunities for all.

The National Curriculum Framework 2005 (NCF2005) highlights the significant role ICT can play in school education. The Vision statement states that The ICT Policy in School Education aims at preparing youth to participate creatively in the establishment, sustenance and growth of a knowledge society leading to all round socio- economic development of the nation and

Global competitiveness. Mission is to devise, catalyse, support and sustain ICT and ICT enabled activities and processes in order to improve access, quality and efficiency in the school system. The studies on successful ICT implementation reveal the key factor being active involvement of the Head teacher with other members in the lead position (Tearle 2003; Sheppard 2003).

With a focus on a particular high school the present study analyses the approaches to Leadership in the change process of managing and sustaining ICT implementation.

Literature review

The Literature review is focussed on two main areas that form the background of the case study.

1. Sustainability of Inquiry based Innovation and 2. School Leadership for sustaining Good Practices

1.Sustainable educational changes in school has five critical and interrelated features: 1 . The processes and effects are deep, broad and durable;2. Supports continuous learning and knowledge sharing fo benefitting everyone in the educational context;3. Upheld by human and material resources which is updated 4. 
No negative impact on the environment; 5. Emphasises the importance of learning from differences through collective efforts for constructive debates and reflective evaluation.(Hargreaves and Fink 2003). In the inquiry approach, the inquiry process is understood as an active creation of the understanding via the mental constructions and based on previous knowledge and considerations of pupils (P. Ross, 2006). During the active cognition ofthe surrounding world by the pupil,thedevelopment of thinking is realised as wellaslearning of the intellectual activities. This conceptof knowledge transfer is in the literature called inquiry, inquiry-based, research, heuristic, discovery, problem, see e.g. Kluge (2011), J. Swaak, T. De Jong and R. Wouter van Joolingen (2004), and S. P. Lajoie et al. (2014).

\section{School Leadership for sustaining Good Practices}

'Setting directions, redesigning the organisation and developing people' are identified by Leithwood and Riehl, 2003 as the three basic principles of successful school Leadership. They emphasise that the model for developing people involves the following steps1. Providing intellectual stimulation 2. Emphasising individualised needs and professional needs; 3 . Setting appropriate models that is consistent with School's values and goals. More recent international research of ICT integration in school settings also verified staff collaboration in the leadership processes as the key to a school's sustainability of implementing ICT (Owston 2007).

Summarising the above studies the factors under focus in the case study was based on the steps taken by Leadership in bringing the New Pedagogy into the education system of the school and the steps to sustain and spread the change from a small scale to whole school reform.

Data and Sources of Data

For this study primary data has been collected. From the designed questions to parents of 30 students of the High School through a Survey questionnaire created on SurveyMpnkey.com. The link to the survey has been shared in the references.

\section{Methodology \& Data Collection}

Findings were collected through questionnaires and semi structured interviews. Short survey in the form of questionnaires was sent to 25 parents for their experience of the Leadership approach of the New pedagogy I.e. New pedagogical approach in inclusion of iPad and SEQTA Learning Management System. Semi structured interviews of The Head Teacher and the Principal of the school. An analysis of the Professional development program and the Communication medium for coordinating was reviewed.

Findings

Findings from the Survey Questionnaire shared with Parents

30 parents were sent a set of 10 questions regarding the new device and LMS introduction to their child studying in grade 6 or 7 . The questions also asked their response t the Leadership approach in introducing and sustaining the New Pedagogy. Following were the trend of the responses to some of the questions.

Statements on the questionnaire were designed to get the Parents responses on the Leadership approach to address Parent community concerns.

Q1. How would you rate the quality of instruction your child is getting after introduction of iPad and SEQTA?

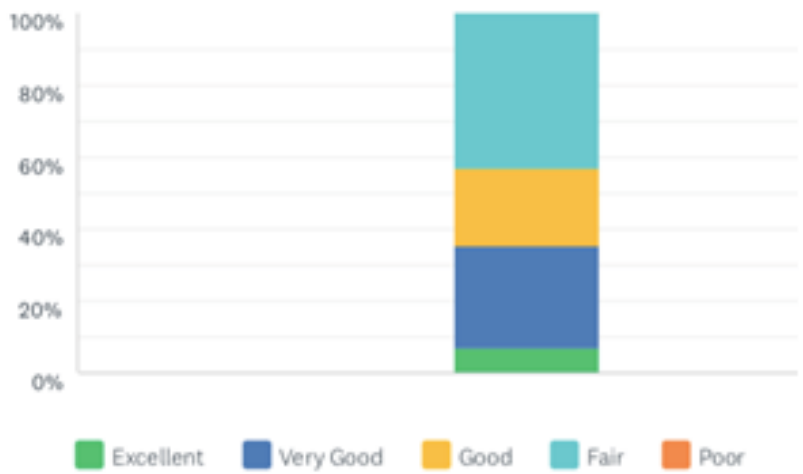

Results of 30 parents participating in the survey

$42 \%$ Fair

$21 \%$ Good

$28 \%$ Very Good

$7 \%$ Excellent

Q2.Have you checked your child's iPad for appropriate use: pictures, webpages etc?

- $\quad$ Answered: 30 Skipped: 0

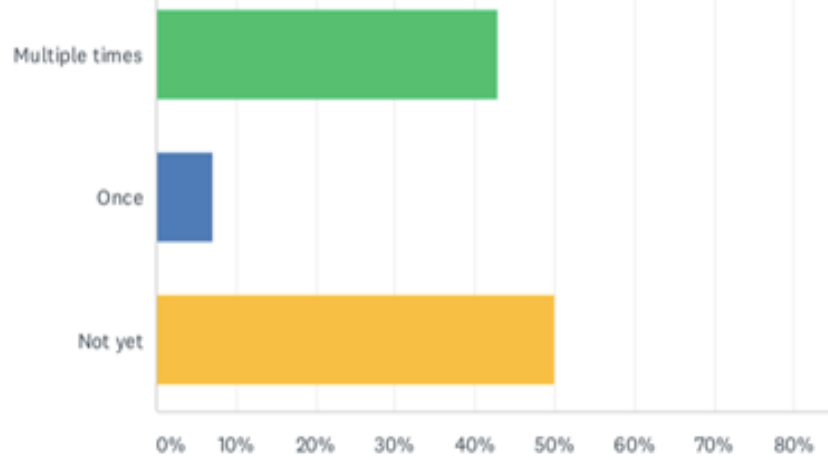

Multiple Times $46.67 \%$

Once $\quad 6.67 \%$

Not yet $\quad 46.67 \%$

Q3. Do you feel your child now asks or is able to ask more questions to teachers and/or other students with the use of the iPad?

- Answered: 30 Skipped: 0•

\begin{tabular}{ll} 
ANSWER CHOICES & RESPONSES \\
Yes & $14.29 \%$ \\
\hline No & $50.00 \%$ \\
\hline Not sure & $35.71 \%$
\end{tabular}

Published By:
Blue Eyes Intelligence Engineering
\& Sciences Publication


The above question intends to understand the impact of technology induced pedagogy on the basic parameter of Scientific Inquiry I.e. asking questions.

Q4. Leadership used following approaches to address the parent community.

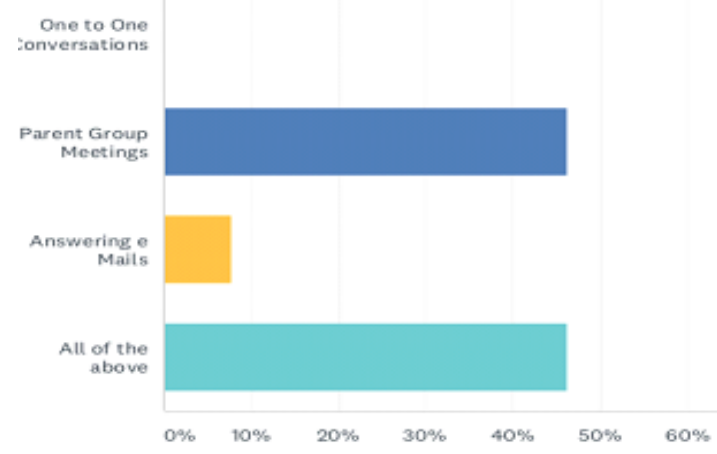

Parent Group Meetings: 46.15\%

Answering e Mails $7.69 \%$

All of the above $46.15 \%$

Q5. Leaderships approach to address concerns of Parent Community.

\begin{tabular}{ll} 
ANSWER CHOICES & RESPONSES \\
- Exceeded expectations & $0.00 \%$ \\
\hline - Met expectations & $76.92 \%$ \\
\hline - Below expectations & $23.08 \%$
\end{tabular}

Findings from Semi structured Interviews with Teachers:

The Learning Management System, SEQTA has been incorporated in daily classroom interaction, mainly in the areas of Lesson Plan, Curriculum projection communication to parents.

iPad has been used mostly in the form of a) Book as for Mathematics the NCERT book is available on the iPad. B) Lesson transaction through Worksheets, relevant videos have been shared by Airdrop.

Professional Development sessions mainly hands on of the LMS and iPad. have taken place in the form of group meetings by Head Teacher and peer Teacher support.

Aspiration for deep learning of the use of iPad as a Pedagogical device.

Review of the Communication strategy used by Head Teacher

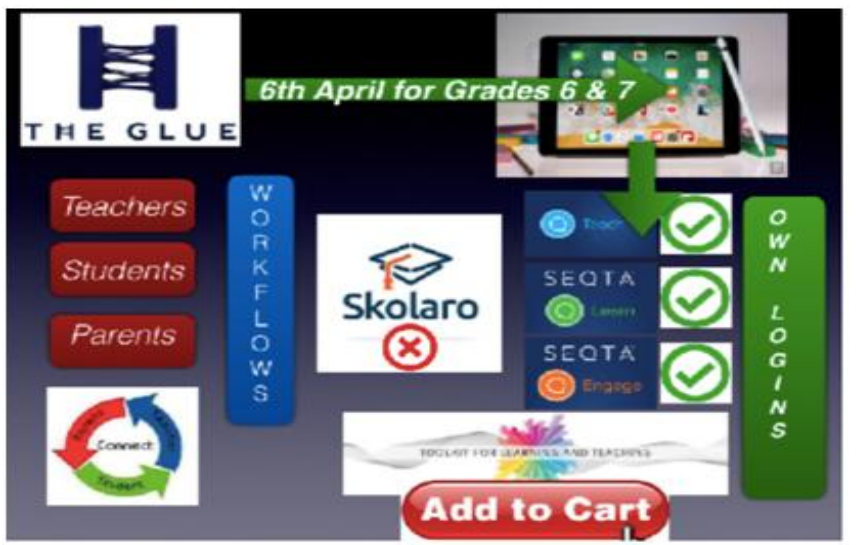

Figure1: Sample slide for communicating the agenda to all stakeholders of iPad and SEQTA LMS inclusion.
This slide would be up on the Principal's Bulletin on the School website for updating information.

Regular Newsletters from the desk of the Headteacher added the element of authentic support from the Leadership.

\section{CONCLUSION}

Despite a small number of participants in the present study the combination of quantitative data through survey and qualitative deceptive analysis provides insight into the school leadership for managing pedagogical innovation such as Inquiry based learning through ICT implementation.

Technology integration in education can only be successful when the human element is taken into consideration. Therefore the key to a successful inventive society is a multidimensional approach to revitalise the education system(Structure, tools and stakeholders) so that it builds learners' autonomy, self efficacy, scientific inquiry skills and creates a common culture that supports innovation in education. The study reflects upon the key success areas in the present school

1. Collaborative and Distributed Leadership approaches taking the human element into consideration while implementing Information and Communication technologies with the immersion of iPad and SEQTA as Learning Management System.

2. Regular updating and Monitoring of the professional development $f$ the faculty members as sustaining motivation agent.

3. Involving and considering parent community as constructive partners in the change process.

4. Staying grounded on the challenges of Monitoring improvement in the Inquiry based Learning outcomes of students while giving them opportunities for holistic development in Arts and Languages while working towards the goal of 'Education for Life'.

5. Digital Technologies have a potential to support Inquiry based learning.

\section{REFERENCES}

1. National policy on Information and Communication Technology in school education; latest revised document 23rd March,2012

2. UNESCO-The sustainable development Goals Report 2017

3. Morrison,K.:Management theories for Educational Change, Paul Chapman, London(1998) scholar

https://scholar.google.com/scholar_lookup?title=Management\%20Theori es\%20for\%20Educational\%20Change\&author=K..\%20Morrison\&public ation_year $=1998$

4. Yih-Shyuan Chen; Yuh-Horng Chen; Shun-Jyh Wu \& Fang-Kai Tang(2013);Leadership for sustaining pedagogical innovations in ICT implementation: A case study of Taiwanese Vocational High School. IADIS International Conference e-Learning.p159-166

5. Allan H.K. Yuen Nancy Law K.C. Wong, (2003),"ICT implementation and school leadership", Journal of Educational Administration, Vol. 41 Iss 2 pp. $158-170$

6. https://www.researchgate.net/publication/308699593_ICT_EDUCATIO NAL_MATERIALS_SUPPORTING_THE_INQUIRY-BASED_LEAR NING [accessed Jun 152019. 